\title{
Archaeology and the Bible
}

\author{
Haggai Misgav
}

In 1967, an inscription was discovered in Tel Deir 'Alla in Jordan (identified by some with the biblical Sukkot). The inscription was written on plaster in black and white ink on the walls of a structure, apparently used for ritual purposes, dating from the eighth century BCE. Its translation reads: "The Book of Balaam, son of Beor. A divine seer was he. The gods came to him at night. And he beheld a vision in accordance with El's utterance.... Balaam arose on the morrow; he summoned the heads of the assembly to him." ${ }^{1}$

The inscription describes none other than the biblical magician Balaam son of Beor, the beholder of visions, and tells his story in language very similar to that used in Numbers 22-24. Though the two stories are not identical, the discovery of the inscription was a cause of great excitement for my late father, Dr. Yehiel Tzvi Moshkovitz, who devoted several years to writing the Da'at Mikra commentary to the book of Numbers. He felt that the inscription gives form and substance to the image of the biblical magician, regarded by the sages as a counterpart to Moses and authenticates the existence of prophecy amongst non-Jews. I remember an incident in which my father enthusiastically described the discovery to my uncle, a Haredi Jew who had studied at the Pressburg Yeshiva. My uncle shook his head skeptically and said, "Why are you so excited about this?" After my father's emotional attempts to explain the importance of the discovery, my uncle again shook his head and said, "And if there wasn't such an inscription, you wouldn't believe that the story was real?"

This anecdote illustrates the essence of the dilemma facing the religious student when he makes use of archeological data to understand the Bible. In my opinion, the expression of scorn, or at least indifference, described in this anecdote, a very common reaction, is camouflage for fear. The possibility of using external data to verify the authenticity of the Bible also raises the possibility of using external data to disprove its authenticity. Is this a legitimate 
way to study the Bible? What is the significance of these external proofs for one who seeks to discover the holiness of the text and his or her own personal commitment to it?

Moreover, even if we set aside the possibility of disproving the authenticity of the Bible (we will return to this subject later), we are proceeding on a path that was unknown to our forefathers, the classical biblical commentators. They were the creators of the intellectual path that Judaism has followed throughout the generations, and these new approaches have not been subjected to their scrutiny. Are the insights that might arise from this new approach consistent with Orthodox thought? Principles of faith are not factual matters; the conceptual structure of Judaism rests on the authority of rabbinic scholars and their instructions. If we expand our conceptual basis to include new information, what will happen to the ancient, preexisting sources of authority? Who will be able to provide spiritual guidance to a generation for whom the conceptual foundations are completely new?

It appears that in the present generation the prevalent religious approach in both the public and private spheres is one of "simple faith." The intention is not necessarily to the Breslov understanding of the term, but rather to a belief that is not grounded in theological analysis and does not accept the authority of reason in matters of faith. This approach sanctifies naïveté not only with respect to issues of thought and philosophy, but also in literary matters. The Bible is not a subject for research and inquiry. Its words are true and just according to their simple, literal meaning. Even ideas like the position expressed by Maimonides in Guide of the Perplexed (3:3) that certain biblical passages are metaphorical have no place in the intellectual world of those who adhere to this approach. This school of thought perceives the use of new information, especially from external sources, and all the more so from nonreligious and non-Jewish sources, as a danger. The more enlightened adherents to this approach are aware of this "dangerous" information, but call its veracity into question and often deride attempts to interpret it.

Among students of the Bible and archaeology within religious Jewish, nonHaredi society, there are those who are less hesitant in their approach to science and secular knowledge and are familiar with academic terminology. However, this relative openness does not change their worldview, nor will they allow it to do so. It is a source of pride for them that their familiarity with external concepts has not damaged their pure faith in the simple meaning of the Torah, and its chronology and stories as they appear. They view all difficulties and challenges as the product of intellectual limitations. For this reason, they favor approaches 
like that of Professor Immanuel Velikovsky (1895-1979), a psychologist and one of the founders of the Hebrew University, who believed that the Bible, as well as the folklore of other peoples, preserved historical truth. ${ }^{2} \mathrm{He}$ therefore believed that it was correct to erase hundreds of years from accepted historical chronologies and even to use natural catastrophes to corroborate biblical chronology, according to its simple meaning.

However, such an approach is not suitable for a person who considers himself to be a member of the scientific community and wants to be accepted as a scholar within the academic world. Even if the Bible is not the subject of one's research, when one takes the first step along this path, one must do some soul-searching and ask: "Who am I? What is my worldview? How far can I allow external concepts and information to penetrate the interpretation of the sources that are the foundation of my life?" This path, of this new type of scholar, is not paved. Earlier scholars did not confront this problem and thus did not address it. Later scholars usually ignored it for the same reason, namely the lack of earlier opinions to follow. Thus, necessarily, the scholar develops new exegetical methods and non-simplistic understandings of the text. Perhaps, at the end of the process, rather than a new interpretation of the Bible, he will have a new formulation of the principles of faith.

In this article, I will attempt to survey the history of archaeology, a relatively new science (not yet 150 years old), and its aims in order to comprehend the network of interrelationships that have formed between it, the Bible, and biblical studies (also a new field, although older than archaeology).

It is current practice to divide the development of archaeology (as far as it relates to periods that impact the Bible) into three stages: classical, new, and postmodern. ${ }^{3}$ The classical approach, called "biblical archaeology," was established in the first half of the previous century. It emphasized important and dramatic historical events - meaning, military campaigns and destructions - and the politics of the ancient world. This school coined the basic terminology of the archaeology of the Land of Israel, which it correlated with historical events and the establishment of political frameworks. Thus, "Iron Age I" signified the period of settlement following the Exodus from Egypt, "Iron Age II" the period of the monarchy, and the preceding Bronze Age is still referred to in museums in Israel as the "Canaanite Period."

For instance, Yigal Yadin identified a layer in his excavations at Hazor as the vestiges of a large fire, indicating destruction, which he dated to the thirteenth century BCE. Sections of this layer included the city's temples, in one of which were found shattered and decapitated idols, deliberately destroyed. 
Its date, determined by independent archeological criteria, corresponds to the time of the conquest of the Land of Israel under the leadership of Joshua son of Nun. Hazor was one of the cities destroyed in the conquest, and one of the three described in the book of Joshua as having been burnt to the ground. Yadin, predictably, identified the remains with the biblical narrative and saw in it proof of the authenticity of part of that narrative: an Israelite invasion that utterly destroyed Hazor, burnt it to the ground, razed its temples, and shattered its idols.

However, other scholars disagreed with the connection he made between the site and the biblical story. They found holes and contradictions in his argument, and inconsistencies between the story and the archeological findings. One of the more famous examples of such a contradiction is the story of Ai. For many years it has been accepted to identify Ai with Et-Tell in the Binyamin region, near the city of Ramallah, both because of the similar meaning of the names and because Et-Tell's location corresponds to the topography described in the Bible. The conquest of $\mathrm{Ai}$ and the sins of Achan lie at the center of one of the longer and more traumatic stories in the book of Joshua. Nevertheless, no archeological evidence of a settlement in the relevant time period, the Late Bronze Age, can be found there. Even archeologists such as Yadin were aware of the problem. They conceded that not every biblical story is exact in all its details and that some stories are etiological legends intended to explain actual historical phenomena. Other scholars, however, tended to give little credence to the accuracy of the biblical narrative and rejected the initial premise that it reflects historical truth.

It must be noted that the specific solution to the problem of $\mathrm{Ai}$ is very simple: it involves rejecting the identification of that particular location with the biblical $\mathrm{Ai}$, with or without proposing an alternative location. It is similarly possible to find individual solutions to almost all of the contradictions and inconsistencies that have arisen. However, the very existence of constant tension between each new discovery and the biblical story, in a kind of eternal ping-pong game of questions and answers, has undoubtedly eroded belief in the Bible as an exact and straightforward historical record.

This school of thought found support in the field of biblical studies. Beginning at the end of the nineteenth century, biblical scholars have assigned most of the biblical narrative a very late date, viewing them as reconstructions of history with varying degrees of accuracy and reliability. This perception of the Bible as an ideological work not bound by historical truth correlated with skeptical perspectives within biblical archaeology. 
Still, proponents of both sides of this controversy defined themselves as biblical archeologists. In other words, every finding and each new theory was inevitably and immediately viewed in the context of one or the other defining biblical narrative. Politics remained the major area of interest, and the central questions revolved around major historical events.

However, in the last quarter of the twentieth century, more in England and the United States than in Israel, a new approach developed that abandoned the "revolving sword" of the Bible and grounded archaeology on a scientific rather than a literary basis. This approach advocates the use of tools drawn from the natural sciences and statistics to analyze findings, and the construction of models of archeological development that do not constantly revert to the Bible for verification. In short, its aim is to transform archaeology from an auxiliary of history into an independent science. It is possible that in those countries, where historical literature from ancient times is relatively scarce, it was easier to implement these changes. The methodology of the study of prehistory also influenced this process. In any case, biblical archeological research published outside of Israel also followed this new trend.

The questions of the "new archaeology" (as it is called by its opponents) are also different. Long term cultural processes and the development of cultural phenomena have replaced historical events and political changes as the focus of interest. Processes examined in this light can impact classical historical conceptions, and shift emphasis from political events to internal developments, social, and otherwise. The period of time examined by this new approach is longer, because a particular historical event, which was seen before as having changed the face of the region with the thrust of a sword, is no longer the focus of research. It has been replaced by slow social developments, which can be detected only through the collection of maximal amounts of data by all methods available to researchers.

While the impact of the new archelogy in Israel would appear to be minor, in the last generation every published archeological report has included various scientific appendices - including physical, chemical, petro-chemical, anthropological, statistical, and other reports - in addition to the standard ceramic and stratigraphic analyses. Because of the rich history of the Land of Israel, and the potential significance of every social, cultural, and historical conclusion, the overarching historical questions still dominate Israeli archaeology. Nonetheless, Israeli archeologists have attempted to interpret findings not only through the lens of ancient literature, but also by means of models based on other branches of science. 
The continuing debate about the historical accuracy of the biblical narrative has recently been ignited by a new/old attempt to explain a finding from the Iron Age I according to sociological models, and to view the characteristic settlement pattern in the Land of Israel in this period as the product of internal developments in Canaanite society. To clarify the matter, I will explain some basic concepts and information.

Iron Age I is characterized by the wide distribution of a new type of settlement in Judea and Samaria. These settlements, called "conquest settlements" on the basis of the biblical story, include a small number of residential units, about twenty rooms, each of which apparently housed one family, attached to each other in a circular structure so that the back walls of all the units together formed an exterior wall. In the center of the circle was a large courtyard used for cooking and other daily tasks. The ceramic remains at the sites are typical of the period, and are poorly manufactured relative to those of the preceding late Bronze Age culture. Many hundreds of such settlements are scattered across the central highland region of the Land of Israel. They reflect a nonurban society based on clans, lacking centralized leadership, and poor in resources and technology. The Canaanite cities, most of which still existed in this period in the plains and valleys, were much larger, richer, and better fortified.

These data can be interpreted in one of two ways. On the one hand, there are many parallels between these findings and the books of Joshua and Judges: a fragmented, leaderless, tribal society, subject to relentless political pressure from its neighbors. On the other hand, it is hard to believe that the weak, nomadic society represented by these archaeological discoveries invaded and overcame Canaanite culture in a swift, decisive war as described in Joshua-especially as Canaanite culture was not in any way defeated, as we have seen. Part of the problem lies with understanding the biblical narrative itself. It is difficult to reconcile the idyllic picture of the first part of the book of Joshua with the scattered and besieged tribes of Israel described in the second part and in the beginning of Judges. It is no wonder then that many scholars have tried to construct an independent explanation for this archeological phenomenon. They have demonstrated that the same process was repeated in different periods in the history of the Land of Israel: the decline and fall of an extensive urban culture that, after a dark age of some two centuries, was replaced by a new culture. In most of these cases, the reasons are internal: climatic catastrophes or demographic changes. The new scholars argued that this explanation could be adopted in this situation as well, because these are similar phenomena that occurred in the same region. 
Therefore, the conquest settlements are a "dark age," the product of internal developments that led to a change in the lifestyle of part of the Canaanite population and the adoption of more convenient social frameworks suited to the new conditions of the region, and, ultimately, to the development of a new identity and consciousness. Support for this opinion can also be found in the similarities between the settlement period ceramics and Canaanite ceramics, as well as the similarity of the houses in both periods and even perhaps in their architectural development. Therefore, according to this approach, there was no conquest and settlement as described in the Bible, but instead a local culture that changed its character and created a new culture.

The controversy between these two schools of thought continues even today. As is to be expected, there are also intermediary positions. There are those who advocate a more complex model: the peaceful penetration of tribes from outside the Land of Israel who settled alongside the Canaanite cities. On the basis of an analysis of the regional spoken languages and the types of tools they used, it may be conjectured that these tribes came from the east bank of the Jordan River. Over the course of time, as a result of demographic and economic pressures, conflicts erupted between the old and new cultures. The Israelite kingdom that had coalesced from the settler tribes emerged from these conflicts. The process of settlement itself would have taken a long time, certainly more than the few years depicted in Joshua.

Because the founders of classical biblical archaeology were either learned religious Christians or ardent Zionist Israeli scholars, the new archaeology was perceived as "post-Zionist" and intended to undermine Jewish nationalistic, if not necessarily religious, values. Although the new scholars themselves for the most part strongly object to these labels, this image was easily adopted by the opponents of the new approach, and, as a result, the debate has shifted from the professional to the ideological realm. Reference to the worldview of a scholar makes it easier to ridicule his views by revealing, as it were, his destructive, hidden, and politically motivated agenda. In my opinion, those who have chosen to defend the classical position in this way need to work harder. The other side's arguments are legitimate and cannot be dismissed with irrelevancies.

To reconcile the biblical picture with these new theories, one must go back to the Bible itself and attempt to read it from a new perspective. It will soon become clear that, in discussing the settlement period, one can in fact begin with the wanderings of the family of the Patriarchs, and see their three hundred years in the Land of Israel, during which they settled, traded, multiplied, and 
even intermingled with the local inhabitants, as the beginning of a long process that came to its conclusion in the days of Joshua and the judges. Various references in less commonly read biblical books, for example, the evidence in Chronicles of Israelite settlements at the time of the subjugation to Egypt (1 Chron. 7:20-29), hint at ambiguity in the settlement process. The book of Judges describes a non-chronological development, and, in fact, the settlement process was long and drawn out, with ups and downs, and the gap between Israelites and Canaanites was not so great. Intermittent wars accompanied this process, from the war of the sons of Jacob in the story of Dinah, to the wars of Joshua, and up until the scattered and decentralized wars of the judges. Perhaps the social and cultural process depicted by archaeology is not so far from the simple meaning of the biblical text.

It must be noted that many important scholars call attention to the fact that, in general, when all is said and done, the historical and archeological information at our disposal correlates with the general outline of the biblical narrative. The social structure of the Middle Bronze Age corresponds to the stories of the Patriarchs; the period of settlement, however, as we define it, corresponds to the period of the consolidation of the nation of Israel; there is strong proof for Israelite monarchy, despite disagreement about the existence of the united monarchy. The campaign of Shishak, the rise of Assyria, and the destruction of Samaria and Judah all left a clear mark in the archeological remains.

Moreover, several findings reveal an impressive correspondence with the biblical narrative. I will discuss three of these. Firstly, the altar on Mount Ebal, a defined square structure dated by its excavator to the beginning of the settlement period, is reminiscent of the Israelite altar described in the Bible. Remains of kosher animals were found surrounding the altar; the remains include that of the fallow deer (yahmor), which while not itself a sacrificial animal, could have served other purposes for those performing the sacrifices. The location of the altar corresponds closely to the details of the story of the altar erected by Joshua on Mount Ebal (Josh. 8). Although many have challenged this identification, no convincing alternate has yet been proposed.

The excavator of this altar, Adam Zertal, also discovered a city in Tel El-Ahwat in Wadi Ara that was built according to a plan not found anywhere else in the Land of Israel, but which has parallels in Sardinia, the home of the one of the tribes of the Sea Peoples called the "Shardana." (The Sea Peoples were known in the Bible as the Philistines, after the name of one of their other tribes.) The site was apparently a storage area for war chariots. Many factors connect these findings to the biblical story of Deborah: Sisera (his name is not 
Semitic, and there are similar place names in Sardinia) set out from this area to wage chariot warfare against Barak son of Abinoam (Judg. 4). The identification of this city with Harosheth-goiim (4:2) is plausible.

The third example, the Tel Dan inscription, is more complicated. The inscription, discovered in the early 1990s, describes the victory of a king of Aram over a coalition that included Joram son of Ahab, the king of Israel, and Ahaziah son of Joram, the king of Judah. The inscription is written in Aramaic, and was discovered piece by piece, over the course of time. The scientists in the laboratories of the Israel Museum reconstructed the text by finding points of connection between the fragments. In the following translation, the words and letters within square brackets are additions made, as far as possible, on the basis of internal similarities within the inscription and the linguistic rules of ancient Aramaic. On the evidence of its location and archeological considerations, the inscription was dated to the second half of the ninth century BCE. The following translation of the inscription is based on the reconstructed text:

(1) $[\ldots]$ and cut $[\ldots]$

(2) $[\ldots]$ my father went up against him in war at $[\ldots]$

(3) And my father lay down and he went to his fathers. Now the king of

(4) Israel had gone formerly into the land of my father. But, then, as for me, Hadad made me king.

(5) And Hadad went before me, and I departed from the seven [...

(6) $[. .$.$] my kingdom and I killed [seve]nty kings who harnessed [thou-$ sands of]

(7) chariots and thousands of horsemen. [I killed Jeho]ram son of [Ahab]

(8) King of Israel, and I killed [Ahaz]iahu son of [Jehoram]

(9) king of the house of David. And I made [their towns into ruins and turned]

(10) their land into $[\ldots]^{4}$

(11) other $[\ldots]$

(12) over Israel [...]

(13) siege upon $[\ldots]^{5}$ 
Based on the names of the kings of Israel and Judah, which are reconstructed with reasonable certainty, it is the universally accepted opinion that the author of the inscription was Hazael, the king of Aram-Damascus, who, according to both the Bible and contemporary Assyrian records, reigned at the same time as these kings. In the inscription, Hazael apparently claims that he killed both kings. Thus, alongside an impressive verification of the biblical narrative's description of the contemporary political constellation and the joint death of the kings, there is also an apparent contradiction: the Bible ascribes their deaths, at the hand of Jehu, to internal Israelite upheavals, and does not connect them in any way to the king of Aram-Damascus (see 2 Kings 9).

It is not difficult to resolve this contradiction. Certain words in the inscription can be read in a way that weakens the connection between Hazael and the deaths of the kings. It is possible to cast doubt on the historical value of the inscription as a typical self-glorifying text. Clever ways can be found to combine the biblical text with the inscription by raising the possibility of a secret conspiracy between Hazael and Jehu, in which Hazael arranged a temporary calm and a lull in the fighting between Aram and Israel out of a common cause with the rebel king anointed by Elisha.

However, these three proposed solutions raise a fundamental problem that illustrates the dilemma sketched out at the beginning of this essay. Reading the words differently (qtalu instead of qitelti in lines 7-8) does not solve the problem because the biblical narrative does not connect the death of the kings to the battles of Hazael at all; the injury of Joram described in 2 Kings 9:15 is not a sufficient explanation. Casting doubt on the historical value of the inscription because its author might have glorified himself is spurious, and raises the question of what internal criteria can be used to access sources' reliability. Is it possible to pinpoint an independent gauge for establishing the reliability of a text? Is the meticulous detail of the biblical text truly an indicator of its reliability? Perhaps the fact that the author (Jeremiah according to rabbinic tradition and, in any case, someone from the generation of the destruction of the Temple) wrote long after the time of the events casts doubt on the Bible's reliability. Is the fact that the inscription was written for the purpose of self-adulation a reason to reject it? Perhaps the fact that its author lived at the time of the events described, combined with the fact that a description of the death of two kings was not part of the usual template for these inscriptions, enhances its credibility? If so, perhaps this is the beginning of a new approach to assessing the reliability of a biblical story from a critical perspective? 
The third solution raises an even more interesting problem. If we deduce from the inscription that there was a conspiracy between Hazael and Jehu, we are not merely closing a gap. Closing gaps is not a particular problem for the religious student of the Bible. The sages themselves in many places filled in missing details, sometimes even when the story could be understood without them. However, in this case, we return to a biblical story that lacks any apparent holes, and find within it new meaning because of an archeological discovery. This implies that before the discovery our comprehension of the story was impaired by the absence of important information. What does this say about all the other cases in which we lack external information?

It seems to me that this example teaches an important message: not to content oneself with the traditional interpretations of the great commentators, because the traditional method of learning is no longer the only way to discover the truth. "Rabbi Joshua son of Levi said in the name of Bar Kafra, 'One who knows how to calculate time periods and constellations and does not do so, Scripture says of him: "[those] who never give a thought to the plan of the Lord, and take no note of what He is designing" (Isa. 5:12)." " In this vein it can be said, "One who studies the Bible and does not make use of archeological research, Scripture says of him: '[those] who never give a thought to the plan of the Lord." Because the modern world gives us tools that we never had before to understand the background of the Bible, we must make use of them. We have no right to reject or ignore them by arguing that they are irrelevant to the eternal meaning of the Bible, or that if the Bible did not provide historical details it is a sign that there is no need for them. The example before us clearly demonstrates that this is not the case, and that the meaning of the Bible is different from what it appeared to be without the external information.

Another, very different, problem is the role of the prophet. If in fact Jehu prepared his rebellion in advance, with careful political strategy, Elisha the prophet did not anoint a surprise candidate, but took advantage of a political process taking shape without his intervention and infused it with his own urgency. If so, what can we conclude about the prophet's knowledge, about his ability to see that which is concealed, the degree of initiative in his actions, or his relation to the world around him? He tried to manipulate reality, but was himself manipulated to no less an extent, perhaps more. What can be learnt from this about the phenomenon of prophecy, its function and aims?

Our use of archeological information-and we must use it because it is here to stay-should not only push us to blaze new trails in interpreting the 
straightforward meaning of the Bible, but should also force us to reformulate our beliefs, and perhaps even the principles of belief themselves.

In recent years a new trend with postmodern characteristics has developed within archaeology. Scholars began to pay attention to the cultural interpretation of discoveries, the ideas and outlooks that can be identified behind the buildings and artifacts. In this vein, there are those who are searching their excavations for information about those people who, until now, have not been at the center of scholarly attention: women, villagers, and inhabitants of frontier communities, desert cultures, and political and cultural borders. This third stage in archeological research reflects a new postmodern understanding. In place of the hubris of attempting to fully understand the past that motivated the early excavators, and led to the formation of the "new archaeology" and its expansion into other scientific areas, there is a growing awareness that the information at our disposal is not only a function of the perspective of the excavator, but is also based upon connections and interpretations. The methods of researching the past at our disposal do not lead us to the past itself, nor do they bring the past to us. They merely provide us with a peephole that is by nature limited in its direction, scope, and shape. This understanding is more than just a recognition of the limitations of scientific research. It also entails the recognition of the legitimacy of other windows on the past and its interpretation, among them the Bible.

For the religious person who wants to study archaeology, this approach is undoubtedly more comfortable than others. The intimidating confrontation between these two fields of knowledge, two methods to understand our origins, is giving way perhaps to the possibility of quiet cooperation. Perhaps this is the beginning of a new revolution. The scholar who decides to take this approach to the sources of information available to him, as he comes to discover the past through the evidence in the Bible, encounters no direct, complete, or exclusive evidence about a specific event. He encounters a text intended to reflect these events, not to describe or represent them. At the end of this long journey, we are faced with the awareness that the Bible is a story about past events; it is not a record of past events. We must read it as we read any other story. We must search within it for hidden literary contexts, and recognize the possibility that the actual order of events differed from the way in which the story is told (the sages preceded us in this in their realization that "there is no chronological order in the Torah"). We must be prepared to read the text synchronically as well as diachronically, or as a circular narrative, or according to other literary constructs. We must accept the possibility that perhaps certain stories 
are meant to be understood metaphorically (Maimonides already interpreted several stories of the prophets in this way). We must read the phrases repeated several times in the first part of the book of Joshua - "so that no one escaped or got away" (Josh 8:22), or "they crushed them, letting none escape" (11:8) as reflections of the subjective impression of the victor, rather than an objective record of events. In short, we must regard the Bible as an interpretation of history, presented as a narrative, rather than an exclusive account. We must understand that it is not the events themselves that mold our consciousness, but our perception of them as formed by the biblical story-by the word of God and by the hand of His prophets.

I will conclude with a rabbinic debate about archaeology_specifically, paleography - at the center of which lies a dilemma, similar to those raised above, that positions the faith and knowledge of the simple believer against contradictory historical-archeological information:

Rabbi Yose said: Ezra was worthy to have received the Torah on behalf of Israel if Moses had not preceded him. ... And even though the Torah was not given through him, its writing was changed through him... Why is it called Ashurit? Because it came with them from Assyria. . . . It has been taught: Rabbi said: The Torah was originally given to Israel in this [Ashurit] writing. When they sinned, it was changed into ro'etz [or da'atz, meaning "Hebrew"] But when they repented, the [Ashurit characters] were returned as it is written: "Return to Bizzaron, you prisoners of hope.' In return [I] announce this day: I will repay you double" (Zech. 9:12). Why [then] was it named Ashurit? Because its script was approved [me'usheret].

Rabbi Shimon b. Eliezer said on the authority of Rabbi Eliezer b. Parta, who spoke on the authority of Rabbi Eliezar ha-Moda'i: This writing did not change at all, as it is written: "The hooks [vavei] of the posts" (Exod. 26). As the posts have not changed, neither have the hooks [the letter vav]. Again, it is written, "and to the Jews in their own script and language" (Esther 8:9). As their language has not changed, neither has their writing. ${ }^{7}$

The question discussed by the sages in this passage, which dates to the second century $\mathrm{CE}$, is an historical question with theological and halakhic implications: In which script was the Torah given? The Torah that we have now is written in a script that is universally known as Ashurit. At that time, the Samaritans were living in the Land of Israel, and they possessed an almost identical Torah, excepting certain fundamental changes, such as its claim for the 
centrality of Mount Gerizim. The Samaritan Torah was written in a different script, universally known, even by the sages, as Ivrit (Hebrew) script. But if their script is Hebrew and ours is not, what is the origin of our script, the Ashurit? And what does this imply about the sanctity of the script and of the text itself, and about the authenticity of our faith as opposed to that of the Samaritans?

Three perspectives are represented in this debate. The most radical opinion is ascribed to the earliest of them all, Eliezer ha-Moda' $i$, a priest and the uncle of Bar Kokhba, who lived in the first half of the second century. He argued that the Torah was given in our script, which was never replaced or changed in any way. This is an approach that refuses to recognize the existence of any development in the Jewish religion. "What has been is what will be, and what has been done is what will be done, and there is nothing new under the sun" (Eccles. 1:9). It is not far removed from the view that says, "Anything new is forbidden by the Torah."

Rabbi, who lived at the end of the century and on whose shoulders rested the fate of the entire People of Israel, decided to cooperate with the world rather than fight against it. He was the first for whom the title Nasi (prince) became part of his name-Rabbi Yehuda HaNasi-and, in this respect, he was the heir of the previous holder of the title, Bar Kokhba. Rabbi was prepared to acknowledge that a change had occurred in the script of the Torah. Evidence exists, even if its origin is foreign. All agree that the alternative script is called Ivrit. He respected the historical tradition of Rabbi Yose, the first speaker in the discussion, who lived in the previous generation. However, the halakhic and historical tradition compelled him to only partially accept the opinion of Eliezer ha-Moda'i, and to thus create an intermediary position: the Torah was given in this script but it was forgotten. The authority of the sages to innovate, including the legitimacy for his own numerous halachic innovations, was grounded in the fact that they were, in fact, restoring authority to the Torah. The world has a system, but it is circular.

Rabbi Yose was the historian of the group. Rabbi asked Rabbi Yose's son, Rabbi Ishmael, to share with him the historical traditions of his father. On one occasion, Rabbi Yose refused to take a preliminary fundamental position concerning Roman culture, either positive or negative, although he ran the risk of severe punishment. ${ }^{8}$ He could not close his eyes to historical information, and was prepared to reexamine his positions in view of reality. As opposed to his two colleagues, the earlier and the later, he was prepared to recognize the implications of his understanding and to accept the existence of process and development: "This was true once, but is no longer." The Torah was not given in our holy script. The Samaritans actually possess 
this ancient script, but it is no longer holy because Ezra had the authority to change it.

This debate is not only historical or political, and concerns more than rabbinic authority. The debate is about what is perhaps the most important concept in Jewish thought: holiness. Both Rabbi Eliezer ha-Moda'i and Rabbi equate antiquity with holiness. Holiness is objective, an integral part of something that cannot be changed. For this purpose, Rabbi was prepared to create new conceptual frameworks, but not to forfeit the basic principle.

Rabbi Yose defined the concept of holiness differently. Antiquity does not convey holiness. Whatever is consecrated by the people, the leaders, the sages, and the halakhah is holy. Rabbi Yose, the historian, was prepared to redefine his beliefs in light of new information from an external source, from his observation of the surrounding situation. Holiness does not determine the halakhah; halakhah determines holiness.

Luckily this debate does not concern a halakhic question. Halakhic decisions are universally binding. In this case there is no authoritative judgment, and all three opinions remain valid. Everyone and every generation can, and perhaps must, choose its own path, according to its worldview, according to the truth, and according to its understanding.

"Common sense is the fundamental principle. The Torah was not intended for someone lacking reason. Intellect is the angel that mediates between man and his God." 9

\section{Endnotes}

1. “Deir 'Alla Inscription," Livius.org: Articles on Ancient History, 20 March 2016, http://www. livius.org/sources/content/deir-alla-inscription.

2. His two major works were Worlds in Collision (1950) and Ages in Chaos (1952), both translated into Hebrew.

3. The new archaeology developed in the 1970s. Postmodern archaeology originated in the 1980s, and gathered strength toward the end of the twentieth century. For further information see S. Bonimovich, "Parshanut tarbutitit vetekes mikrai: ha'arkeologia hamikrait be-edan ha-postmoderni" [Cultural interpretation and biblical ceremony: biblical archaeology in the postmodern era], Cathedra 100 (2001): 27-46.

4. The word "destruction" should be added here.

5. Christopher Rollston, “The Tel Dan Inscription,” Bible Odyssey, 25 June 2017, http://www. bibleodyssey.org/en/people/related-articles/tel-dan-inscription.

6. Babylonian Talmud, tractate Shabbat 75a.

7. Babylonian Talmud, tractate Sanhedrin 21b-22a.

8. Babylonian Talmud, tractate Shabbat 33b.

9. Rabbi Abraham Ibn Ezra, Introduction to the Commentary on the Torah. 